\title{
Surdez e Escolarização: Língua, Subjetividade e Alfabetização
}

\author{
Lauro Araújo Mota
}

\begin{abstract}
Resumo: O presente trabalho é resultado de um conjunto de discussões e reflexões que vêm sendo realizadas pelo autor sobre questões relacionadas aos processos de produção da surdez envolvendo aspectos como a constituição da subjetividade, o uso da língua de sinais e as possibilidades de letramentos e alfabetização, bem como as várias semioses que podem ser utilizadas pelos/com os surdos na escola. O objetivo do trabalho foi refletir sobre a condição de surdez e problematizar como ela implica e mobiliza o campo escolar. A pesquisa bibliográfica foi embasada nos trabalhos de Souza (2006), Martins (2006), Nascimento e Lima (2015), Solé (2005), Luz (2013). As discussões centram-se, num primeiro momento no papel da linguagem (falar e ouvir mais especificamente) na constituição da subjetividade das crianças surdas e, posteriormente, aborda aspectos relacionados à escolarização dos surdos sob o viés da leitura e da escrita e a necessidade de utilização de outras semioses para assegurar a aprendizagem desses alunos.
\end{abstract}

Palavras-chave: Surdez. Escolarização. Leitura e escrita.

\section{Deafness and Schooling: Language, Literacy and Subjectivity}

\begin{abstract}
This work is the result of a series of discussions and reflections that are being carried out by the author on issues related to deafness production processes, involving aspects such as the constitution of subjectivity, the use of sign language and literacies possibilities and literacy, as well as the various semiosis that can be used by / with the deaf at school. The objective was to reflect on the condition of deafness and discuss how it implies and mobilizes the school field. The literature review was based on the work of Souza (2006), Martins (2006), Nascimento e Lima (2015), Solé (2005), Luz (2013). The discussions focus at first on the role of language (speaking and listening more specifically) in subjectivity of deaf children, and later approached aspects related to the education of the deaf under the bias of reading and writing and the need to use other semiosis in order to ensure learning of deaf students.
\end{abstract}

Keywords: Deafness. Schooling. Reading and writing.

\section{Introdução}

O objetivo do artigo é refletir sobre a condição de surdez e problematizar como ela implica e mobiliza o campo escolar. A pesquisa bibliográfica de natureza qualitativa foi embasada nos trabalhos de Souza (2006), Martins (2006), Nascimento e Lima (2015), Solé (2005), Luz (2013) dentre outros.

\footnotetext{
${ }^{1}$ Pedagogo- Universidade Estadual do Ceará- UECE. Especialista em História, Sociologia e Psicologia Aplicada à Educação- Universidade Regional do Cariri- URCA e em Língua Brasileira de Sinais- Universidade Federal do Piauí- UFPI. Mestre em Educação- PUC CAMP. Doutorando em Educação: Psicologia e Educação- UNICAMP. Docente da Universidade Federal do Piauí-UFPI.

E-mail: lauro.mota@ufpi.edu.br
} 
Id on Line Revista Multidisciplinar e de Psicologia

Id on Line Multidisciplinary Journal and Psycology

No texto serão discutidas questões relacionadas à condição de surdez e a constituição da subjetividade; o uso da língua de sinais e as possibilidades de letramentos, alfabetização e as várias semioses que podem ser utilizadas pelos/com os surdos na escola e sobre a necessidade e possibilidade de construção de uma escola bilíngüe.

Partimos do pressuposto de que a escola enquanto instituição social reflete e refrata os posicionamentos, ideologias, modos de perceber e enunciar a surdez. Ela está imersa num contexto social, político e cultural que favorece e estimula tanto a reprodução de um determinado modelo de homem, de educação e de sociedade bem como também oferece elementos para sua transformação. Para compreendermos a educação que se oferece aos surdos, hoje, é preciso entendê-la como um processo histórico mais amplo e que também reflete todo o movimento nos quais outros grupos desfavorecidos também passaram e passam na luta por acesso a educação escolar.

\section{Língua, Surdez e Subjetividade}

$\mathrm{O}$ acesso a uma língua constitui-se como um dos elementos fundantes e estruturantes da subjetividade humana. Para os surdos, principalmente por conta das diferenças lingüísticas e as (im) possibilidades, algumas vezes, de uso da língua oficial do país em que vivem, sofreram/sofrem um processo, muitas vezes, de invisibilização social que reflete diretamente na sala de aula quando ali se encontram incluídos.

Sobre a invisibilidade do surdo Martins (2006) relata uma importante experiência que teve como Intérprete de Língua Sinais juntamente com um aluno surdo que acompanhava em um curso de ensino superior. A autora apresenta um episódio em que durante um seminário, e com o consentimento do professor, as luzes foram intencionalmente apagadas, ficando ela e o aluno surdo invisíveis para a turma. Diante da situação ela se questionou: "Como puderam nos esquecer com tantos meses de contato $i$ Como esqueceram que minhas mãos precisavam das luzes para dialogar com o aluno surdo? Por que o professor aceitou passivamente a situação; será que ele esqueceu que tem um surdo em sala de aula?" (MARTINS, 2006, p. 137). O apagamento da surdez e seu processo de invisibilização não existe apenas na escola, mas também em muitas instâncias e instituições sociais, muitas vezes ou, na maioria das vezes, se materializa na negação da surdez ou na tentativa terapêutica da normalização dos surdos através do re-estabelecimento da fala e da oralização.

O acesso a uma língua é (não importando se de natureza oral auditiva ou visual gestual) um dos elementos fundantes da constituição da subjetividade. A constituição da subjetividade depende, 
Id on Line Revista Multidisciplinar e de Psicologia

Id on Line Multidisciplinary Journal and Psycology

em parte, da forma como cada ser humano foi desejando e nomeado no mundo, com o mundo e para o mundo.

Quando um bebe nasce, ele é imerso na linguagem e a língua dos pais vai, aos poucos, atribuindo significado às experiências do bebê. Ao mesmo tempo em que adquire a linguagem, vai se constituindo como sujeito. A linguagem não se instala no bebe em um momento único, ela ocorre num processo, assim como a constituição da subjetividade. (NASCIMENTO, LIMA, 2015, p. 165).

O que o discurso parental projetou na criança antes de seu nascimento e como os pais lidam com a criança real, surda, tem implicações diretas no seu reconhecimento e na sua aparição. A forma como os pais lidam com o filho com deficiência e com a ferida narcísica produzida por ela tem impacto na aceitação e no desenvolvimento psicológico da criança.

O sujeito é antes de tudo gestado no/pelo discurso e no desejo do Outro [que podemos nomear como o casal parental] ou daqueles que exerceram essa função. Geralmente a mãe é aquela que alimenta, veste, embala e satisfaz não apenas as necessidades biológicas mais urgentes do bebê, mas também unifica o seu corpo através de sua fala, interpretando seus gestos, expressões afetivas, nomeando o mundo e significando-o.Constituímo-nos a partir das múltiplas e diversas relações, posições e posicionamentos que nos possibilitam aparecer enquanto sujeitos.

\begin{abstract}
Aparição é, no seu grau máximo, assumir-se entre Outros alguém que é singularização de toda a humanidade, a realização plena e criativa de si no mundo comum a partir da experiência sensorial, afetiva, lingüística e cultural pela presença de um Outro responsável por mim enquanto rosto. Por existir a partir de laços éticos e comunicar um alguém e um mundo, é uma experiência de realização de si que revela algo dos aspectos ontológicos, psicológicos e sociológicos essenciais do humano. (LUZ, 2013, p. 33-34).
\end{abstract}

Nesse processo de aparição a fala da mãe ou de qualquer outra pessoa que desempenhe esse papel funciona como estímulo organizador dos sentidos da criança e mesmo para uma criança com surdez profunda impedida de ouvir a voz humana o ato de falar da mãe é extremamente importante porque desperta nela o desejo e a curiosidade de compreender o que estar sendo enunciado (SOLÉ, 2005).

A autora ressalta ainda que a voz materna possui tanto a função tranqüilizadora para o bebê como antecipadora de sua chegada e também de sua separação. Mais do que isso, a função psíquica da fala/linguagem é estabelecer um corte na relação dual mãe-bebê possibilitando o acesso ao mundo simbólico. Solé (2005) em consonância com Vasse (1974) faz um paralelo entre as aberturas do ouvido e do umbigo. 
O corte umbilical introduz o recém-nascido em um novo modo de relação: o da aliança. E a partir desse momento, o corpo a corpo com a mãe é mediado pela voz tanto do bebê quando da mãe e do pai. O umbigo é o corte; a voz é a subversão desse corte. A sutura definitiva do umbigo explica o fato de não existir percepção umbilical. Não codificado, não é possível decodificá-lo. Este corte definitivo e inaugural do fluxo sanguíneo primordial tem como conseqüênciaa renúncia à passividade de uma vida parasitária e o início de uma atividade sensorial subordinada, de um lado, pela periodicidade da satisfação orgânica e, de outro, pela permanência do desejo da mãe. (SOLÉ, 2005, p. 100-101).

Como indicado anteriormente, à voz materna tem um papel unificador do corpo da criança $\mathrm{e}$ na constituição de sua subjetividade e o desconhecimento da surdez por parte da família pode, de certa forma e até certo ponto, salvar o bebê e a família da dor provocada pelo diagnóstico precoce e o seu impacto na relação, pois o que ocorre geralmente é que quando os pais recebem o diagnóstico de surdez silenciam diante do filho. Calam-se e nada mais é dito a criança e para ela. Uma exclusão do filho surdo do discurso materno. Esse silêncio e desprazer oriundos da não interação verbal dos pais pode ser significado pelo bebê como um sentimento de abandono (SOLÉ, 2005).

Ainda sobre a produção da subjetividade de crianças surdas Nascimento e Lima (2015) discutem a produção de um novo sujeito histórico que vem surgindo recentemente graças aos avanços da medicina, que é o surdo que tem a língua de sinais como sua primeira língua e que possuem ao mesmo tempo um implante coclear. Uma aparente contradição uma vez que o implante coclear tem como objetivo possibilitar a escuta e a comunicação via fala em sujeitos com surdez profunda que já se comunicam através da língua de sinais.

O trabalho das autoras citadas anteriormente discute as motivações e os desejos de famílias que fizeram a opção de oferecer a seus filhos surdos um implante coclear e a capacidade de ouvir algum som. Esse novo aluno que surge (surdo, bilíngue e implantado) demanda da escola outras e novas possibilidades de ensino e aprendizagem que rompam com o modelo vigente baseado na normalização dos surdos através da reabilitação da fala.

Para Skliar (2004) a escola destinada aos surdos durante muito tempo foi baseada na oralização influenciada pelo modelo clínico terapêutico constituindo-se como um espaço que pretendeu dar ao surdo aquilo que lhe faltava substituindo o espaço pedagógico pelo espaço clínico e transformando o aluno em paciente. $\mathrm{O}$ discurso pedagógico foi atravessado de termos médicos e clínicos como "reabilitar", "reforçar", "restituir" constituindo-se assim como mais um mecanismo de marginalização social desses alunos.

Como aponta Skliar (2010, p. 6) é preciso “(...) criticar os discursos clínicos, a medicalização, a ouvintalização na educação dos surdos" para que a educação passe a ser vista e percebida como um importante instrumento de desenvolvimento cognitivo, de aprendizagem, emancipação e autonomia dos surdos rompendo com os modelos existentes que reproduzem situações de opressão e 
Id on Line Revista Multidisciplinar e de Psicologia

Id on Line Multidisciplinary Journal and Psycology

marginalização desses alunos na escola, e que “(...) não aceitando a língua de sinais dessas pessoas e centrando os processos educacionais na visão de reabilitação e naturalização biológica" (ALVES, FERREIRA, DAMÁZIO, 2010, p 7) corroboram para a manutenção de modelos educativos que negam as diferenças e procuram normalizá-las nos vários âmbitos da sociedade.

Desse modo, Souza (2006) ao refletir sobre os impactos provocados pelo Decreto $n^{\circ} 5.626$ que reconhece a Libras como língua oficial dos surdos no Brasil nos mobiliza a pensar na ilusão que construímos sobre o caráter monolíngüe de nosso país.

\begin{abstract}
Ao longo do tempo, essa construção histórica passou também a ser eficaz para mascarar o fato de que outras línguas constituem o Brasil, como aquelas das nações indígenas, das comunidades de imigrantes, das comunidades surdas, entre outras. A ilusão de um país monolíngüe. A ilusão de um país monolíngüe em Português faz com que as demais línguas (em torno de 200), que compõem uma unidade nacional profundamente heterogênea, tornem-se invisíveis, naturalizando-sena sociedade e na escola nosso suposto monolinguismo. (SOUZA, 2006, p. 271).
\end{abstract}

A autora indica ainda a necessidade de ultrapassarmos a ideia de que a escola se constitui como uma comunidade monolíngüe e para que consigamos superar e nos libertarmos da ilusão de que “(...) no Brasil todos os brasileiros natos falam o português” (SOUZA, 2006, p.270). Souza analisa alguns documentos oficiais e constata que “(...) nos PCNs Adaptações Curriculares, os falantes de outras línguas (excetuando-se os indígenas) são considerados como pertencentes ao grupo de brasileiros com necessidades especiais. Dito de outro modo: no Brasil, o normal é falar e escrever em português" (p. 270).

Dessa forma podemos pensar o reconhecimento e a importância da Língua Brasileira de Sinais ser ensinada na escola como primeira língua dos surdos e de como isso rompe com toda uma estrutura já existente no que diz respeito a temporalidades, formas e modos de ensinar e aprender considerados "normais". O aluno surdo, para que consiga aprender, necessitará antes de tudo do acesso a uma língua para que possa se comunicar, desenvolver e expressar seu pensamento.

\title{
Sobre as Múltiplas Possibilidades de Ensinar os Surdos a Ler e Escrever
}

A educação escolar através do ensino sistematizado dos conteúdos científicos possibilita outras formas de desenvolvimentos das funções psicológicas superiores (atenção, memória, pensamento, sentimento, emoção, inteligência) através da mediação dos instrumentos semióticos construídos ao longo do desenvolvimento cultural e da presença do Outro que fala, aponta, indica e nomeia o mundo para a criança (VYGOTSKY, 2001; 2004) 
Id on Line Revista Multidisciplinar e de Psicologia

Id on Line Multidisciplinary Journal and Psycology

Sobre os instrumentos culturais e a relação com o Outro como elo mediador do processo de aprendizagem das habilidades escolares de leitura e escrita, Lins e Cabelho (2016) trazem para discussão importantes questões sobre a alfabetização dos alunos surdos. Discutem a importância das imagens (em suas múltiplas concepções, formatos, mídias) no processo de ensino e aprendizagem de alunos surdos. Apresentam a experiência de construção de objetos de aprendizagem (OA) como artefato digital que favorece a aprendizagem por ser um suporte (software livre) que congrega semioses que possibilitam comunicar-se com o mundo e no mundo utilizando o canal visual gestual e considerando as necessidades dos surdos, respeitando (...) a língua de sinais e todos os seus parâmetros, principalmente o movimento, expressões faciais e corporais e seus aspectos tridimensionais- importantes para garantir os aspectos gramaticais da língua de sinais (QUADROS, KARNOPP, 2004, LEBEDEFF, 2014 apud LINS e CABELLO, 2016)

Outra questão percebida pelas autoras com relação à alfabetização dos surdos diz respeito à construção do material didático bilíngue que deve contemplar arquivos com imagens e vídeos para que os surdos possam compreender a língua em toda sua riqueza, movimento e estrutura, como apontado. Uma questão crucial que envolve o uso de tecnologias para a alfabetização dos alunos surdos está relacionada diretamente à formação docente (alguns casos incipiente, fragmentada, superficial) e à dificuldade, desconhecimentos de alguns docentes sobre o uso das tecnologias, ou o que geralmente acaba acontecendo em grande parte das situações que é a simples transposição de atividades do suporte em papel para o suporte digital. Nesse caso, investir na formação docente também se constitui um grande desafio.

Ainda sobre a importância do uso das imagens na prática pedagógica, Lins (2014) discute como a escola utiliza as imagens para controlar e regular os olhares, para disciplinar os sujeitos e como nessa dinâmica ocultação/desvelamento se produzem determinados tipos de sujeitos. Uma pedagogia das imagens como algo que seduz e enreda o sujeito num perigoso jogo de submissão e dominação para definir espaços e lugares a serem ocupados socialmente. No entanto, além da denúncia de uma prática de uso das imagens que podem ser utilizadas com fins de domesticação dos olhares, corpos e inculcação ideológica, Lins (2014) sinaliza o importante papel que o uso das imagens como de outras semioses tem como potencializador da prática pedagógica. A autora ressalta a importância de um olhar crítico sobre as imagens, sobre o ver e como ler as imagens. Sinaliza em consonância com Ángel Quintana (2012 apud LINS, 2014) a necessidade de buscar o obtuso e não o óbvio.

Indo além da questão das imagens, pensando e refletindo sobre a formação de leitores surdos proficientes Lins (2012) problematiza a leitura e os modos de ler. Traz para o debate motes como leitura e leitores cânonicos, autorizados e principalmente os chamados leitores na contramão e suas 
Id on Line Revista Multidisciplinar e de Psicologia

Id on Line Multidisciplinary Journal and Psycology

diferentes formas/possibilidades de ler, compreender, interpretar e inter-agir no mundo e com o mundo.

Nessa investigação Lins (2012) parte de um estudo empírico com surdos alfabetizados que, ao revelaram suas trajetórias de leitura enunciam sobre sua condição de sujeitos e sobre como as práticas de leitura se constituíram/constituem como elemento de inserção num mundo ouvinte e que tem na fala sua centralidade. Os sujeitos investigados revelam o que perceberam desde muito cedo, a leitura, principalmente na escola [leitura canônica, autorizada] é, ainda, um dos principais instrumentos de inclusão no grupo social. Ler ou fingir que leu e entendeu [o texto narra como uma das entrevistadas utilizava desse artifício para permanecer na escola] é muito mais do que uma estratégia de sobrevivência na escola. A leitura, acredito que não somente para os surdos dessa pesquisa, tem um sentido/possibilidades de pertencimento ao grupo e a si mesmo.

\section{Considerações Finais}

Diante do que foi exposto durante o texto podemos considerar que o que precisa ser problematizado e tensionado diz respeitos aos instrumentos semióticos utilizados para alfabetização, tanto de crianças ouvintes quanto surdas, questionando a hegemonia e a legitimidade da língua oral (principalmente a escrita na sua variante padrão) mais valorizada socialmente. É preciso ressaltar que, como existem sujeitos com diferentes capacidades de aprender, alguns com limitações orgânicas e sensoriais, faz-se necessário criar ou adaptar instrumentos e mecanismos para que estes sujeitos [com limitações e deficiências] também possam ter acesso aos conhecimentos produzidos pela humanidade e vinculados principalmente pela escola.

No caso dos surdos que utilizam o canal visual gestual como forma de comunicação e apreensão da realidade é imprescindível à construção de instrumentos e mecanismos que considerem a imagem, os movimentos, os gestos e a própria escrita dos sinais como forma legítima de acesso à cultura. A grande questão que se coloca com relação à aprendizagem dos surdos tem um caráter muito mais político do que pedagógico. Diz respeito às concepções de sociedade, de homem e de educação que são construídas num determinado período histórico e que são compartilhadas como necessárias para assegurar a ordem e simetria de determinada sociedade.

Desse modo, pensar no uso de outros instrumentos semióticos para ler, escrever e nomear o mundo é uma forma de transgressão e de ruptura com o que está estabelecido, dado, muitas vezes pronto e acabado. Provoca, instiga e ao mesmo tempo gera um estranhamento nos sujeitos acostumados com a rotina mecanizada da leitura e da escrita em suportes tradicionais (livro, jornal, 
Id on Line Revista Multidisciplinar e de Psicologia

Id on Line Multidisciplinary Journal and Psycology

computador, etc). Construir, inventar, testar outros meios semióticos para que os surdos leiam o mundo é um ato de rebeldia, enfretamento e liberdade que eles precisam aprender a utilizar para se tornarem mais autônomos e independentes.

\section{Referências}

ALVES, C. B; FERREIRA, J. de P.; DAMÁZIO, M. F. A educação escolar na perspectiva da Inclusão escolar: abordagem bilíngüe na escolarização das pessoas com surdez. Brasília/MEC/SEESP. Fortaleza: Universidade Federal do Ceará, 2010. Vol.4 (Coleção A Educação Especial na perspectiva da Inclusão Escolar)

LINS, H. A. de M. Leitores surdos: reflexões a partir de algumas histórias de apropriação. In: LINS, H. A. de M (Org.) Leitores na contramão. Campinas: SP: Edições Leituras crítica, 2012.

LINS, H. A. de M. Cultura visual e pedagogia da imagem: recuos e avanços nas práticas escolares. Educação em Revista. Belo Horizonte. V. 30, n.1, p. 245-260, mar.2014

LINS, H. A. de M.; CABELLHO, J. O ensino de língua de sinais e sua escrita também em questão: tecnologias, temporalidades e valoração numa perspectiva bakthiniana. 2016 (no prelo)

LUZ, R. D. Cenas surdas: os surdos terão lugar no mundo ¿São Paulo: Parábola, 2013.

MARTINS, V. R. de O. O que me torna invisível ¿ A psicanálise como ferramenta para entender o "apagamento" das diferenças na inclusão escolar de surdos. ETD- Educação Temática Digital, Campinas, v. 8, n. especial. p. 135-152, dez. 2006.

SKLIAR, C. Uma perspectiva sócio-histórica sobre a psicologia e a educação dos surdos. In: SKLIAR, C (Org.). Educação e exclusão: abordagens sócio-antropológicas em Educação Especial. $4^{\mathrm{a}}$ Ed. Porto Alegre: Mediação, 2004.

SKLIAR, C. Um olhar sobre o nosso olhar a cerca da surdez e das diferenças. In: SKLIAR, C. (Org.) A surdez. $4^{\text {a }}$ Ed. Porto Alegre: Mediação, 2010.

SOLÉ, M. C. P. O sujeito surdo e a psicanálise: uma outra via de escuta. Porto Alegre: Editora da UFRGS, 2005.

SOUZA, R. M. de. Língua de Sinais e Escola: considerações a partir do texto de regulamentação do Língua Brasileira de Sinais. ETD- Educação Temática Digital. Campinas, v. 7, n. 2, p. 266-281, jun. 2006.

VYGOTSKY, L. S. Pensamento e Linguagem. $2^{a}$ ed. São Paulo: Martins Fontes, 2001

VYGOTSKY, L. S. A formação social da mente. São Paulo: Martins Fontes, 2004. 
Id on Line Revista Multidisciplinar e de Psicoloqia

Id on Line Multidisciplinary Journal and Psycology

\section{Como citar este artigo (Formato ABNT):}

MOTA, L.A. Surdez e Escolarização: Língua, Subjetividade e Alfabetização. Id on Line Revista Multidisciplinar e de Psicologia, Outubro de 2016, vol.10, n.31, p. 16-24. ISSN 1981-1179.

Recebido: 21/07/2016.

Aceito: $29 / 07 / 2016$ 